These data show that a high prevalence of G-6-PD deficiency in Sardinian men is associated with duodenal ulcer and suggests that this deficiency may be a cofactor in the pathogenesis of the disease. This association is difficult to interpret and in any case our findings should be compared with data from other countries where the prevalence of G-6-PD deficiency is similar to that found in Sardinia.

$S$ ADDIS N D'Ovidio

Ospedali Riuniti

Sassari, Italy

'Siniscalco, M, et al, Nature, 1961, 190, 1179. Addis, S, Applicazioni Bio-mediche del Caliolo
Elettronico, 1971, 4, 330 .

\section{Cranial arteritis}

SIR,-Dr J W Paulley (21 May, p 1348) may well be right that loss of sight in cranial (giant-cell) is due to occlusion of the ophthalmic artery. Nevertheless, in 1943 Johnson et $a l^{1}$ did describe "occlusion of the upper branches of the central retinal artery and vein" in one of their patients and in 1946 we $^{2}$ published the necropsy findings in another patient in whom "both optic nerves showed marked softening" and whose retinal arteries showed obliteration of the lumen by cellular fibrous tissue, with the characteristic histological findings on section. We also described the extensive large-artery involvement that may be found in temporal arteritis, as did Gilmour'3 in 1941 and Sproul ${ }^{1}$ in 1942.

Dr R V H Jones (p 1355) is right in calling attention to the dramatic nature of headache encountered in elderly patients with temporal arteritis. Much of the early literature emphasised this, as we ourselves did in 1946. It has been our clinical practice over the past 30 years to regard such severe headaches in the elderly (in the absence of Paget's disease, bone secondaries, or hypertensive crises) as warranting the presumptive diagnosis of temporal arteritis. Descriptions such as those given by Dr Jones are characteristic.

W Trevor CoOKe Walsham-le-Willows,
Suffolk 1 Johnson, R H, Harley, R D, and Horton, B T,
American fournal of Ophthalmology, 1943, 26, 147
' Cooke, W T, et al, Quarterly fournal of Medicine, $1946,15,47$

${ }^{3}$ Gilmour, J R, Fournal of Pathology and Bacteriology,

1941, 53, 263.
Sproul, E E, New York State Fournal of Medicine, $1942,42,345$.

SIR,-My recent experience of temporal arteritis has been in line with that of $\mathrm{Dr}$ R V H Jones (21 May, p 1355), who has alerted us to the graphic language which may be used to describe the headache.

In 1974 a man attended me for the first time in 30 years (he had even failed to register under the NHS in 1948) complaining of a bad one-sided headache of recent onset. It was not difficult to judge that one attendance in 30 years for a modest complaint like headache indicated a more than ordinary headache. Biopsy confirmed arteritis. In March this year a man came to me complaining of severe headaches of recent onset with prostrating paroxysms of pain; previously he had never had headaches. Six months earlier he suffered a thrombotic glaucoma but did not seek medical advice for 16 days, which indicates a stoic pain threshold. Biopsy confirmed the arteritis.

Alastair A McInnes

Raunds, Wellingborough, Northants

\section{Safety of children in cars}

SIR,-To add a further point to recent correspondence (Dr A West, 2 April, p 908), I should like to point out that it is not just when hiring cars on the Continent that safety seats for children cannot be provided. My husband, 1-year-old daughter, and I return to England frequently and have made repeated efforts to hire a car with such a seat. My most recent inquiry was greeted by the, admittedly off the cuff, reply that it is illegal to hire a car with a baby seat. In my opinion it should be illegal not to provide such a seat if requested, as it is extremely dangerous to travel with an unrestrained 1-year-old, and frankly impossible unless there is an adult other than the driver in the car. I am at present in correspondence with some of the larger car hire companies regarding this subject but as yet have received no satisfactory answers.

M E M Cochrane

Lisbon,
Portugal

Very early recognition of coronary heart disease

SIR,-I think your leading article (21 May, p 1302) on this subject does a great service in emphasising the very poor predictive value of the recognised "risk factors" such as smoking, etc. This underlines how little we really know about the relevant predisposing mechanisms and their measurement. You also rightly question the value of early detection unless it can lead to useful action.

We shall never fully understand the predisposing mechanisms. Nevertheless, when 20 years ago the serum cholesterol was found to be often raised in coronary heart disease, it was a reasonable decision to deploy money and effort to try to correct this abnormal test. It was just bad luck that lowering the cholesterol does not seem to convey much clinical benefit except in gross hyperlipidaemia.

The search for further abnormal tests in people known to be at risk must go on. Such tests might, but not necessarily will, have prognostic value. If a test could be normalised therapeutically, this treatment stands a good chance of helping patients. If it helped patients we could then deduce more about the pathogenetic mechanisms.

There are a number of continuing studies searching prospectively and retrospectively for abnormal tests. One such test is the nonspecific heparin thrombin clotting time, which may measure released platelet factor 4 and hence reflect platelet "activation." This test is abnormal in all the many groups so far studied of patients known to be at risk. ${ }^{2}$ It can be altered towards "supranormal" in healthy men by a change to a diet of unsaturated fat. ${ }^{3}$ In patients with gross vascular disease this and other tests can be normalised by treatment with clofibrate or an analogue, identified as ICI $55897 .^{\circ}$ This test then might be of individual prognostic value and its correction might convey clinical benefit. This has yet to be determined.

You say, "Most previously fit patients who developed coronary heart disease ... had no conventional risk factors . . ." and elsewhere you say, "Furthermore at present none of our more advanced tests . . . for thrombotic tendency .. . improve the specificity and sensitivity of the predictions." This view is too pessimistic. In so serious a disease even remote clues should be followed, but I submit, sir, that the approach outlined above and the further exploration of these kinds of test are most worthwhile.

J R O'BRIEN

\section{Central Laboratory,}

St Mary's Hospital,
Portsmouth, Hants

'O'Brien, J R, et al, Thrombosis et Diathesis Haemorrhagica, 1975, 34, 483

Dana, B, et al, American fournal of Cardiology, 1976.

38, 9.
O'Brien, J R, et al, Lancet, 1976, 2, 995.

The First Florence Conference on Haemostasis and Thrombosis, 10-12 May, 1977. Abstracts, p 64.

Lipoproteins and Drugs, p 151. Ed D K ritcheviky, R Lipoproteins and Drugs, $\mathrm{p} 151$. Ed D Kritchevsky, $\mathrm{R}$ Publishing Corporation, 1975 .

\section{Tourist hepatitis}

SIR,-I was very interested to see the letter from $\operatorname{Dr} F$ W Best on the above subject (30 April, p 1158). There is little doubt that most physicians prescribe gammaglobulin for travellers on a very empirical basis. Many factors are involved, particularly the availability of the preparation (thus, for example, gammaglobulin is widely available in Canada and no prescription is needed). All biological preparations, especially immunisations, possess the potential to interfere with the "normal" immunological status of the recipient, and the indications for the administration of a particular product should never be immutable.

Although the noted adverse effects of gammaglobulin are relatively few, a "prospective" philosophy of adverse reactions may well be more significant as far as immunoglobulins are concerned, for modern methods of testing for immunological competence are relatively crude and presumably lack the sensitivity to detect subtle alterations in the immunological status of the recipient.

It would hardly seem justifiable to offer gammaglobulin to travellers on short trips to the tropics. Those who are spending a significant time in rural and high-risk tropical areas should be considered as candidates for gammaglobulin, also those with debilitating conditions. The preparation must be used with care in those with a history of repeated blood transfusions (antibodies to gammaglobulin may be present).

A S Meltzer

Health Unit,

Carleton University

Ottawa,

Canada

Effects of tamoxifen in relation to breast cancer

SIR,-The letter by Dr E Ferrazzi and others (21 May, p 1351) concerning the oestrogenic effects of tamoxifen during the treatment of breast cancer deserves further comment. They make reference to the oestrogenic effects of tamoxifen in laboratory animals and suggest that mammary tumour regression in man 
may be related to this oestrogenic property. We have studied the biological effects of tamoxifen in the rat and found that the compound can inhibit the stimulatory effects of concomitantly administered oestradiol in immature and ovariectomised rats, and similarly in mature animals it will inhibit the oestradiol-stimulated changes in the vaginal smear. What is of particular relevance is the fact that tamoxifen also produces atypical oestrogenic effects when administered alone. ${ }^{1}$

Radiolabelled tamoxifen has been shown to bind to the cytoplasmic oestrogen receptor ${ }^{3}$ and initiate the translocation of complexes to the cell nucleus" but, whereas oestradiol provokes cell division, the stimulatory effects of tamoxifen produce endometrial hypertrophy. The partial uterine growth which results is probably due to the inability of tamoxifen to provoke a prolonged and consistent rise in uterine DNA content. ${ }^{1}$ :

Similar effects have been observed in vitro using cultured human breast cancer cells, where it appears that non-steroidal antioestrogens in general, and tamoxifen in particular, have effects other than a simple antagonism of oestrogen action, as they can reduce the activity of some biochemical processes to below control values.

It is therefore apparent that, since tamoxifen can play a positive part in subcellular events as well as being an oestrogen antagonist, then any inappropriate biochemical changes which occur in mammary tumours may have a profound effect on continued growth and homoeostasis. Therefore, even though tamoxifen has the properties of an antioestrogen, its effects as a partial or atypical oestrogen agonist may be of prime importance for its antitumour activity in the post-menopausal patient with breast cancer.

V C JORDAN

Department of Pharmacology,

School of Medicine

Jordan, V C, Cancer Treatment Reports, 1976, 60, 1409

Jordan, V C, et al, Molecular and Cellular EndoJordan, V C, et al, M
crinology, 1977, 7 , 177.

Jordan, V C, and Prestwich, G, Molecular and Cellular

Endocrinology, 19778 , in press.
Lippman, M E, Bolan, G, and Huff, K, Cancer

Treatment Reports, 1976, 60, 1421.

\section{Chemoprophylaxis of malaria}

SIR,-In response to your leading article on chemoprophylaxis of malaria (20 November 1976, p 1215): In Kinshasa, Zaire, Plasmodium falciparum is found in perhaps $95 \%$ of the cases of malaria in the population. Malaria due to $P$ falciparum is easily diagnosed and treated. However, untreated, the morbidity and mortality are high.

Chloroquine is the antimalarial of choice in this area. Chloroquine in doses of 200$300 \mathrm{mg}$ per week is effective in preventing malaria. Chloroquine is effective in treating acute cases of falciparum malaria. The treatment is rapid, can be repeated, and the failure rate is low. The amount of chloroquine given must be determined by the age and weight of the patient. Here many patients have chronic haemolytic anaemia (sickle cell anaemia, etc ... .). These patients have increased folic acid requirements. They must receive additional folic acid to protect them against megaloblastic anaemia. Chloroquine apparently does not affect folic acid metabolism and does not increase folic acid requirements.
Chloroquine should be given weekly for life to patients who have had their spleens removed, whether for sound clinical reasons (trauma, etc) or for questionable, unsupported reasons (for example, sickle anaemia). After splenectomy for any cause there is an increased risk of cerebral malaria due to $P$ falciparum.

One final point: The myth that haemoglobin $S$ protects against malaria is simply not true, at least, not against falciparum malaria. The facts are: (1) that infection by $P$ falciparum results in many deaths in patients with sickle cell anaemia (homozygous S); (2) patients with sickle cell trait (haemoglobin A-S) may have repeated attacks of malaria due to $P$ falciparum. The frequency and severity of these attacks of malaria are the same as in those with haemoglobin A.

Service d'Hèmatologie

F A JoHnson

Institut de Médecine T

L'Hôpital Mama Yemo,

Kinshasa,

Zaire

\section{Royal College of Physicians and fluoridation}

SIR,-Mr R V Mummery (21 May, p 1352) points out that in a comparison of the DMF (decayed, missing, filled teeth) indices in adults over 30 years of age from an area of high $(1.4 \mathrm{ppm})$ and low $(0.25 \mathrm{ppm})$ concentration of naturally occurring fluoride in the drinking water the difference was negligible. He fails to remind your readers that the DMF index is not exclusively a measure of denta decay but includes (M) tooth loss from other causes. In young children the predominant cause of tooth loss is decay as reflected in the DMF values quoted of 3.9 (high fluoride) compared to $6 \cdot 6$ (low fluoride) in 5-year-old children.

However, there is a shift in the cause of tooth loss with increasing age. In adults the proportion of teeth lost because of decay falls, and other reasons for tooth extraction, such as periodontal disease and the patient's attitude to dental health are of increasing importance. ${ }^{1}: 3$

The fact that the beneficial effect of fluoridation is limited to reducing dental decay is undisputed. No claim has been made that fluoridation directly affects periodontal disease. Does $\mathrm{Mr}$ Mummery advocate that we refrain from reducing dental decay in children because they may develop periodontal disease as adults?

\section{Department of Oral Medicine}

and Pathology,

Glasgow Dental Hospital and School

Glasgow

Waerhaug, $\mathrm{J}$, in The Prevention of Periodontal Disease,

ed J E Eastoe, D C A Picton, and A G Alexander, ed J. London, Henry Kimpton, 1971 .

Gray, P G, et al, Adult Dental Health in England and W'ales in 1968 . London, HMSO, 1970.

Todd, J E, and Whitworth, A, Adult Dental Health
in Scotland, 1972. London, HMSO, 1974.

\section{Clinical rheumatology and orthopaedic} medicine

SIR,-Dr P W Blower (28 May, p 1413) hits the nail on the head when he deplores the inadequate provision for orthopaedic medicine. Surveys have shown that one patient in five visiting his family doctor has an orthopaedic non-surgical complaint. Hence it is evident that every orthopaedic team should include a medically orientated doctor dealing with the non-surgical lesions of the moving parts. This was the policy adopted at St Thomas's Hospital, where I was the orthopaedic physician. This collaboration worked well, each type of orthopaedic case being seen by an interested consultant. This arrangement exists today at the Strong Memorial Hospital, Rochester (NY), and again is popular on both sides.

What is now needed is an institute of orthopaedic medicine, ${ }^{1}$ where tuition can be offered all the year round to those anxious to learn this type of work and to physiotherapists who need to learn the appropriate manual methods. Within a year or two one physician could then be sent out to each orthopaedic team in the country, and the most expensive hiatus in our Health Service would be closed, not only on humanitarian grounds but for the benefit of insurance, industry, and sick-benefit funds. The institute exists on paper as a registered charity (secretary: G Symonds, 81 Belsize Lane, London NW3) but lacks funds to get started. Since very little capital outlay is required for orthopaedic medicine, and the clinic would pay for itself many times over, it presents an immediately feasible measure to deal with Dr Blower's fully justified criticism. In Spain Conesa' describes how, when he incorporated the methods of orthopaedic medicine at his rehabilitation centre, its annual cost fell from 24 to 6 million pesetas, and $47 \%$ of the patients got well in one treatment.

JAMES CYRIAX Visiting professor in orthopaedic medicine USA

' Cyriax, J H, Textbook of Orthofaedic Medicine, Vol 1, 6 th edn. London, Ballière Tindall, 1975. 2 Conesa, S H, Incorporaciòn de la Medicina ortopedica Fasc 1 .

\section{Anaesthetic waste gas scavenging systems}

SIR,-I was pleased to see that Professor L Rendell-Baker and Dr R A Milliken (21 May, $p$ 1348) have come to the same conclusion as we did here (19 February, p 506), that active extraction is to be preferred to passive, but I am puzzled by their statement that active systems "are very expensive in terms of energy costs." The DHSS Circular (HC (76)38) on the subject calls for an extraction rate of $301 / \mathrm{m}$ with a negative pressure not exceeding $1 \mathrm{~cm} / \mathrm{H}, \mathrm{O}$. Taking this to be $100 \mathrm{~Pa}$, a simple calculation shows that the theoretical power requirements are 0.005 watt. On the most pessimistic assumptions about losses in the pipe line and low-efficiency extraction pumps it is hard to see how the power requirement per patient could exceed 1 watt, or how this could disturb the most ardent conservationist.

This is not a trivial matter, because the belief that an active extraction system would be expensive was at least partly responsible for the DHSS recommendation that a passive system should be preferred. A similar nonquantitative approach has led to the belief that the scavenged gases could constitute a fire hazard and a chemical hazard to the pumps. A simple calculation again shows that if, as it should be, the expired air is diluted at the point of extraction the mixture could not possibly be flammable, and the possible halothane 